九州大学学術情報リポジトリ

Kyushu University Institutional Repository

\title{
Development of the Multilingual Collaboration System for Farmers of Several Counntries (1): Application of Basic Terminology Translation Dictionary
}

Lee, Kang Oh

Laboratory of Agricultural Ecology, Division of Agricultural Ecology, Department of Plant Resource, Graduate School of Bioresoruce and Bioenvironmental Science, Kyushu University

Nakaj i, Ke i

Laboratory of Agricultural Ecology, Division of Agricultural Ecology, Department of Plant Resource, Faculty of Agriculture, Kyushu University

Nada, Yoichi

Laboratory of Agricultural Ecology, Division of Agricultural Ecology, Department of Plant Resource, Graduate School of Bioresoruce and Bioenvironmental Science, Kyushu University

https://doi.org/10.5109/4604

出版情報: 九州大学大学院農学研究院紀要. 49 (2)，pp.433-440，2004-10-01. Faculty of Agriculture, Kyushu University

バージョン:

権利関係 : 


\title{
Development of the Multilingual Collaboration System for Farmers of Several Countries (Part 1) - Application of Basic Terminology Translation Dictionary -
}

\author{
Kang Oh LEE', Kei NAKAJI* and Yoichi NADA \\ Laboratory of Agricultural Ecology, Division of Agricultural Ecology, \\ Department of Plant Resource, Faculty of Agriculture, \\ Kyushu University, Fukuoka 811-2307, Japan \\ (Received June 30, 2004 and accepted July 13, 2004)
}

\begin{abstract}
In order to share agricultural information through the Internet, the multilingual collaboration system of agricultural production was developed for farmers of many countries. The basic terminology translation dictionary was developed by using several open source programs and free software to translate the basic terminology of multilingual collaboration system. The basic terminology translation dictionary was composed of about 4200 terms in Japanese, Korean and English including 2700 horticulture terms, 1300 agricultural machinery ones, and 150 file names. It was possible for anyone to add other terms on the Internet by the registration and editing subsystem. The basic terminology translation dictionary could be also used to translate the retrieval term for multilingual search engine system to get a lot of agricultural information for Web site in other languages.
\end{abstract}

\section{INTRODUCTION}

With the rapid progress of the Internet, the scene of communications by means of information technology has expanded in various fields. The joint operation at distance in a same field became possible by using the Internet technology (Choi et al., 2002; Lin et al., 2003). In the agricultural field, the advanced Internet technologies were applied to the system for monitoring plants and animals, sharing the agricultural information and carrying out joint work of agricultural production in real time (Cunha et al., 2001; Lopes et al., 2001; Laurenson et al., 2002). However, the collaboration systems have a serious problem of language, because the system was developed by a particular language or English, generally. Especially, the farmers of many countries have a difficulty of language, when they exchange the mutual opinions and comments on the Internet. It is necessary to use the multilingual collaboration system that the farmers can practice the cooperation in their native languages for agricultural production.

The language translation system is one of the most important problems in the development of the multilingual collaboration system for farmers of several countries. To solve the problem, many machine translation systems have been developed in many countries, especially USA, Japan, Korea and Europe (Park and Oh, 1999; Herath et al., 1996; Tou, 2000; Manka and Mili, 1995). Nakamura and Takigishi (2001) developed multilingual

\footnotetext{
1 Laboratory of Agricultural Ecology, Division of Agricultural Ecology, Department of Plant Resource, Graduate School of Bioresource and Bioenvironmental Science, Kyushu University

* Corresponding author (E-mail: knkjfam@mbox.nc.kyushu-u.ac.jp)
} 
mailing list system that the e-mail of the farmers in Japan and Korea was translated into the Japanese and Korean languages. The agricultural production collaboration system for farmers was proposed to solve the language problems, and it was attempted as a multilingual collaboration system (Nakaji and Lee, 2002). Lee and Nakaji (2003) studied the multilingual collaboration system of agricultural production for farmers by using IP camera. Farmers in Japan and Korea were able to exchange the opinions and comments by each native language for the condition of crops in the greenhouse with IP camera images.

In the current study, the basic terminology translation dictionary was developed to translate a lot of terms used in multilingual collaboration and retrieval on Web and in-Site.

\section{MATERIALS AND METHODS}

\section{The concepts of multilingual collaboration system for farmers}

The multilingual collaboration system of agricultural production can be utilized on the Internet by using a broadband communication line. It is important to design the user-friendly screen of the display including IP camera images which present clearly the object such as crops condition in the greenhouse, dairy cattle in the cattle barn, agricultural facilities for production, farm work and so on.

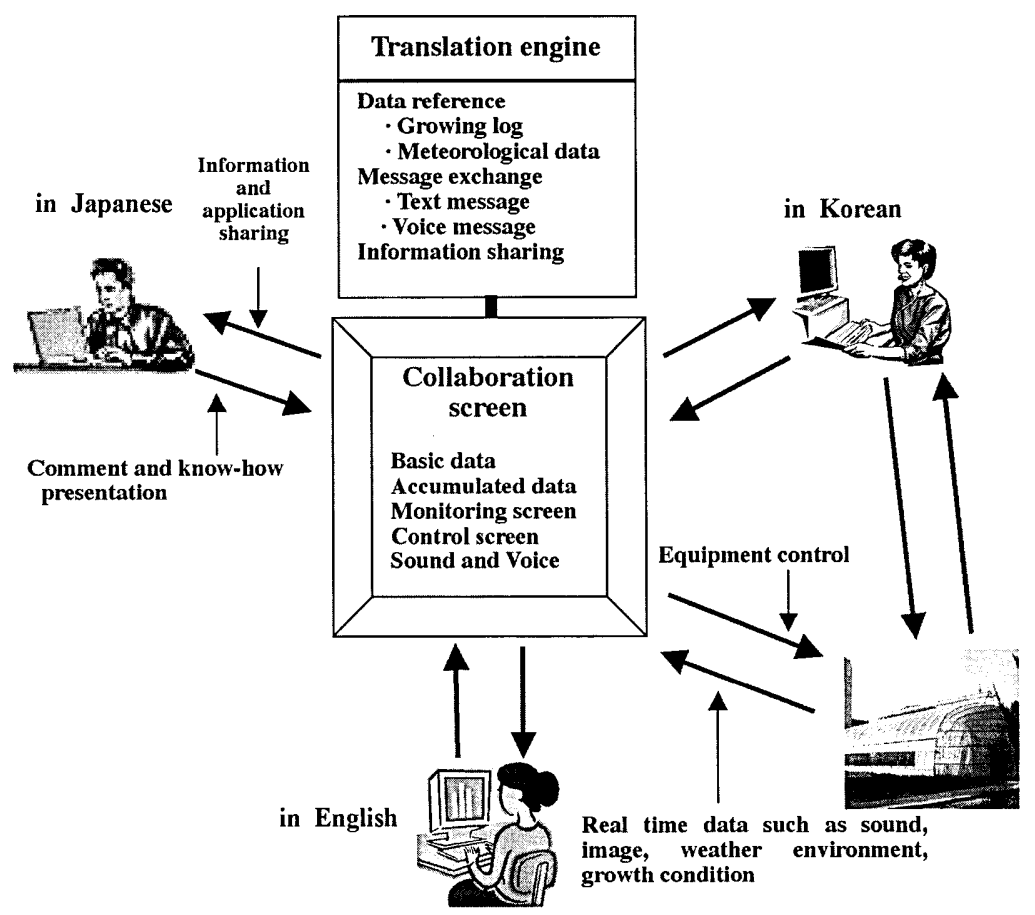

Fig. 1. The conceptual scheme of the multilingual collaboration system for farmers (Nakaji and Lee, 2002). 
Figure 1 shows the conceptual scheme of the multilingual collaboration system for farmers. The farmers using Japanese, Korean and English languages can collaborate for the agricultural production without a language barrier through the Internet by using the multilingual collaboration system. They can observe the agricultural facilities in real time at a distance, share the agricultural information for agriculture production and exchange the mutual opinions or comments about crops condition in the greenhouse. They can confirm basic and accumulated data, monitor and control conditions of the object on the multilingual collaboration screen. They can also join work in their own native languages by using the language translation system. In this study, the type of Client-Server was adopted for the multilingual collaboration system of agricultural production.

\section{The development of basic terminology translation dictionary}

The basic terminology translation dictionary was developed to translate exactly fundamental terms shown on the screen of the multilingual collaboration system by using several open source and free software programs such as Apache server, PHP script language, Mysql database and Microsoft IME standard 2002. Figure 2 shows the structure of the basic terminology translation dictionary. The basic terminology translation dictionary was composed of basic terminology of communications, agricultural technical terms, data base names and file names in Japanese, Korean and English corresponding to the code numbers. At the present, the translation dictionary contains about 4200 terms, including 2682 horticulture terms, 1315 agricultural machinery ones, and 150 file names. Many other terms can be stored easily in the database through the Internet by using the registration and editing subsystem developed.

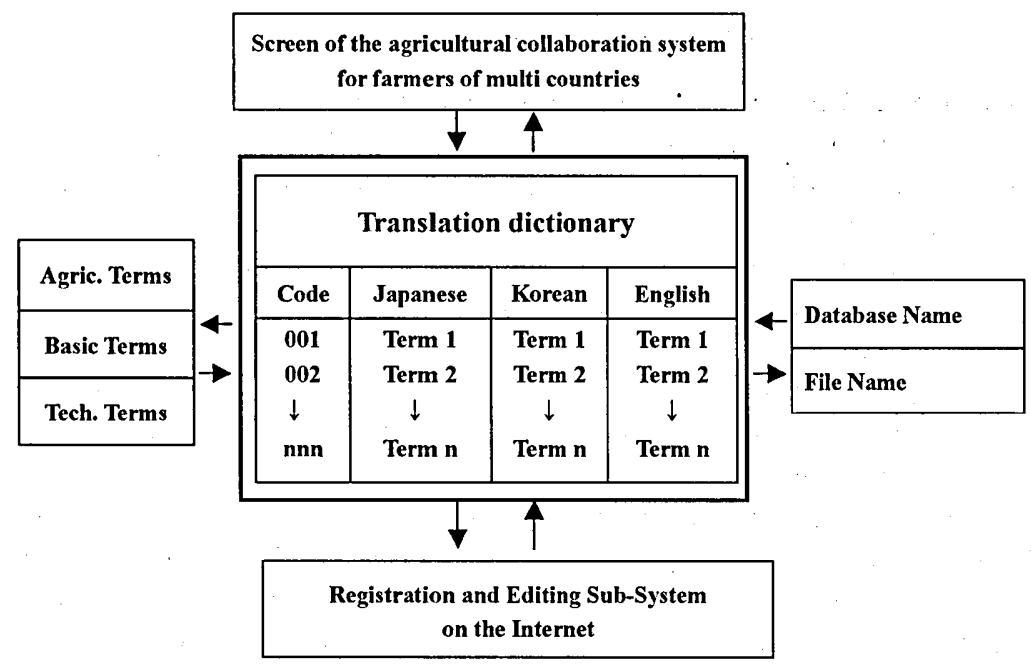

Fig. 2. Structure of the basic terminology translation dictionary. 


\section{The conversion principle of the basic terminology}

The basic terminology translation dictionary can be used for farmers to get more agricultural information on the Internet. Figure 3 shows the conversion principle of the basic terminology translation dictionary. When one term or phrase of Japanese, Korean and English is inserted and translation button is clicked, the term or phrase is displayed in three country languages on the multilingual collaboration system:

For example, though the Japanese farmer who does not understand Korean wants to retrieve Korean Web site, he/she can't get the Korean retrieval term usually. As the Japanese term is exactly translated into Korean by using the basic terminology translation dictionary as far as the term is registered, he/she can obtain many information of Korean Web site by the Korean retrieval term translated.

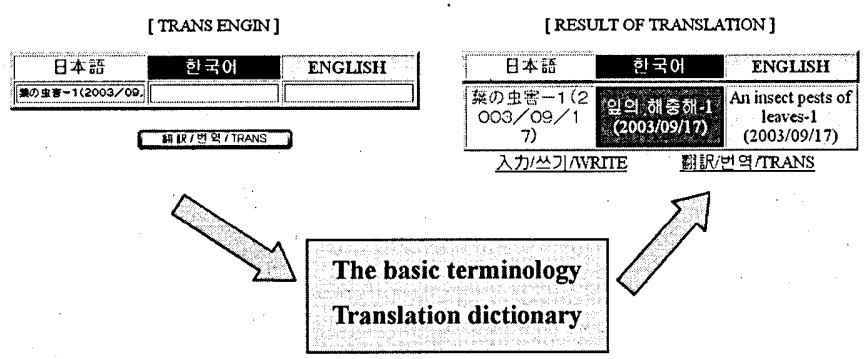

Fig. 3. Conversion principle of the basic terminology translation dictionary.

\section{RESULTS AND DISCUSSION}

\section{Translation of multilingual collaboration system screen}

Figure 4 shows the main screen of multilingual collaboration system for farmers. Farmers could observe fully the crops condition in the greenhouse by including IP camera images in the main screen.

Two subsystems were designed to translate terms and sentences on the main screen at the high accuracy. Firstly, the basic terms displayed on the screen were perfectly translated into the corresponding language of each country by the basic terminology translation dictionary and translation engine. Secondly, the contents of data files such as cultivation log and observation log were translated into the language of each country by using Web ASP translation services if necessary. Because the accuracy of translation depended on the kind of Web ASP translation service, more than 20 services were investigated. As a result of bench mark tests on text file, MS Excel file and MS Word file recorded crop condition respectively, the service of Mobico \& Sysmeata Co. (Korea) showed the highest accuracy of translation among Japanese, Korean and English of all. By the method of translation, farmers could practice the exchange of mutual opinions and the joint work in real time for the crop condition in the greenhouse by their own native 
languages. But it appeared the accuracy of translation by using Web ASP translation service lowered gradually, as the translations between Japanese and Korean were repeated alternately.

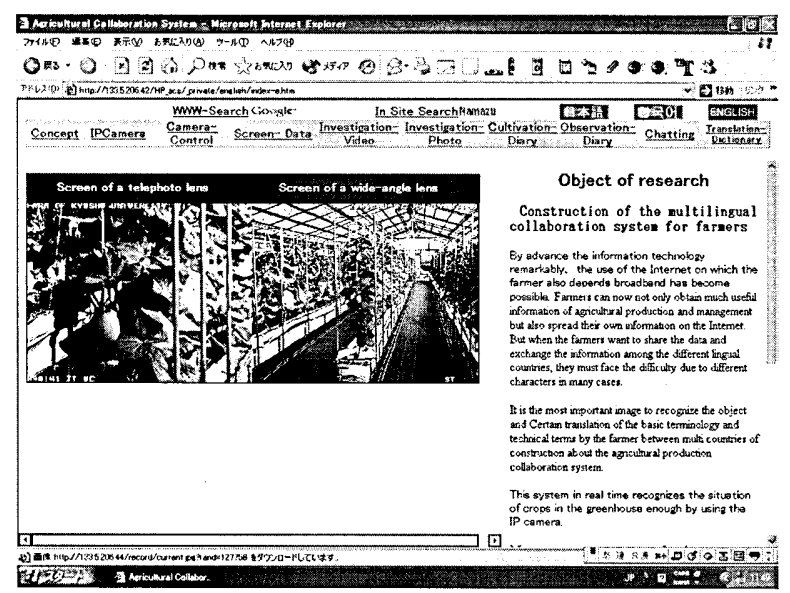

Fig. 4. Main screen of the multilingual collaboration system of agricultural production for farmers of many countries.

\section{To use the basic terminology translation dictionary}

The basic terminology translation dictionary was able to add the terms through the Internet at any site. Figure 5 shows the screen of registration and translation result for basic terminology translation dictionary on the multilingual collaboration system. In the figure, the term of 'agriculture' was registered in the basic terminology translation dictionary by editing mode screen, and 'biological control' was translated in three countries languages by the basic terminology translation dictionary. It is necessary for the trilingual users of Japanese, Korean and English to input the terms in order to translate exactly as well as possible. Though we afraid that the accuracy lowers, more than one bilingual user are available for registration of new terms in the basic terminology translation dictionary. The basic terminology translation dictionary is also used to translate the retrieval terms for the multilingual search engine system.

\section{To collaborate the agricultural production by language translation system}

Farmers can observe crops condition in the greenhouse in real time on the multilingual collaboration screen by IP camera at any site. However, it is difficult to observe always crops of greenhouse on the screen, and a special cultivation work is sometimes necessary in crop growth period. In order to share the cultivation activities, it is very important to make good use of multi media database of the cultivation work by using digital camera and video camera besides the IP camera. In the case of melon cultivation, farmers can confirm precisely the cultivation work such as sowing, transplanting, training, pollinating, fruit hanging, bagging and agricultural chemicals anytime by multi media 
database. Figure 6 shows the photographs of the fruit hanging explained in Japanese, Korean and English respectively, on the multilingual collaboration system.

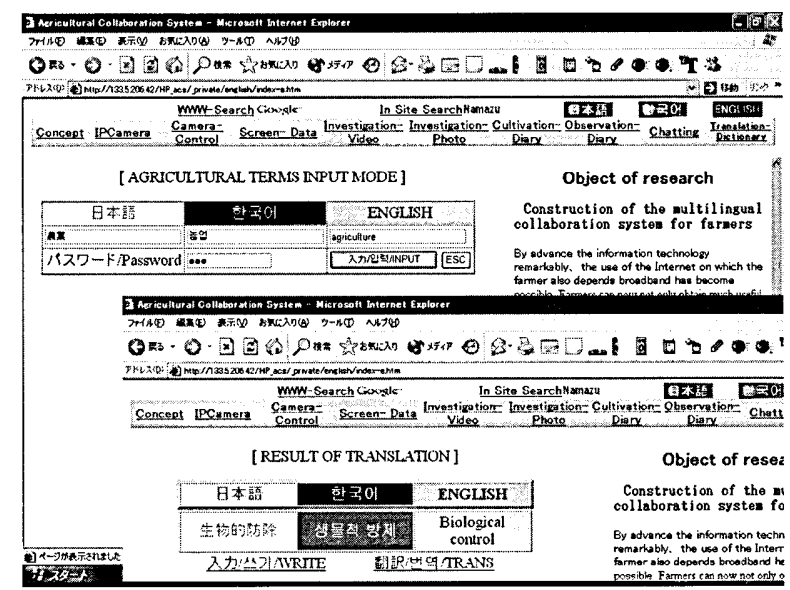

Fig. 5. The screen of registration and translation result for basic terminology translation dictionary on the multilingual collaboration system.

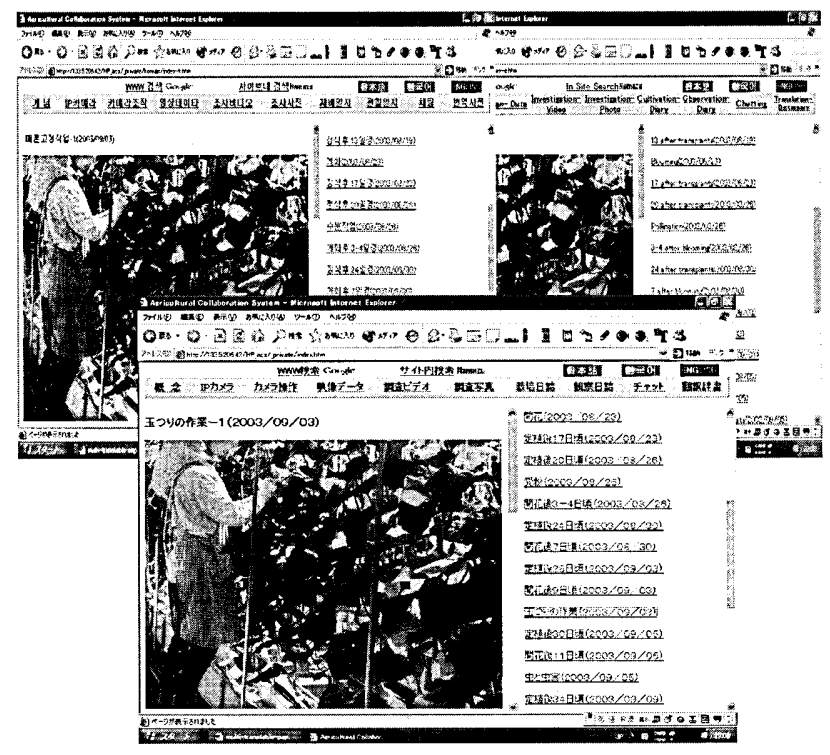

Fig. 6. Sharing the photograph data of work of fruit hanging on the multilingual collaboration system of agricultural production for farmers of each country. 
Figure 7 shows the screen of translation of cultivation log by using the Web ASP translation service of Mobico\&Sysmeta. The cultivation log and observation log are updated on the Internet by farmers, and the files are translated according to each country language by using the Web ASP translation service. Farmers could understand the cultivation $\log$ without a language barrier.

Farmers can exchange the mutual opinions in real time by using the text chat of the Web ASP translation service as shown in Figure 8. The Korean farmer can write the com-

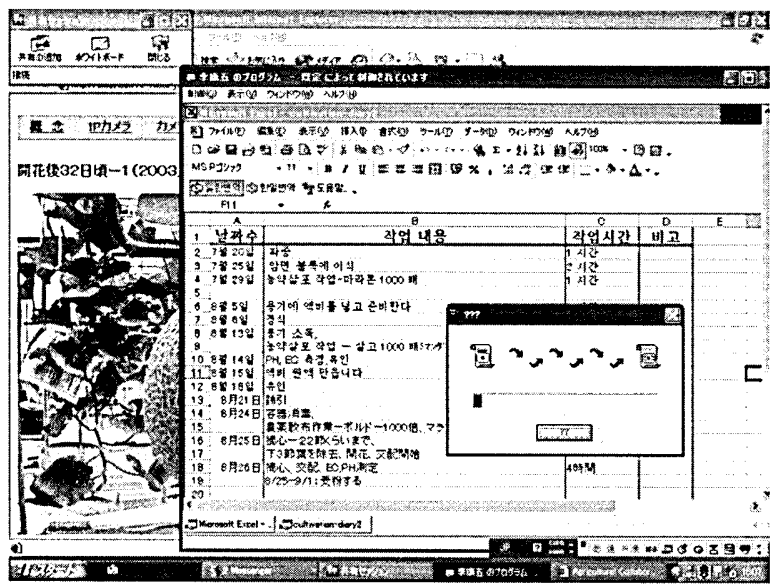

Fig. 7. The screen of translation of cultivation log by using the Web ASP translation service.

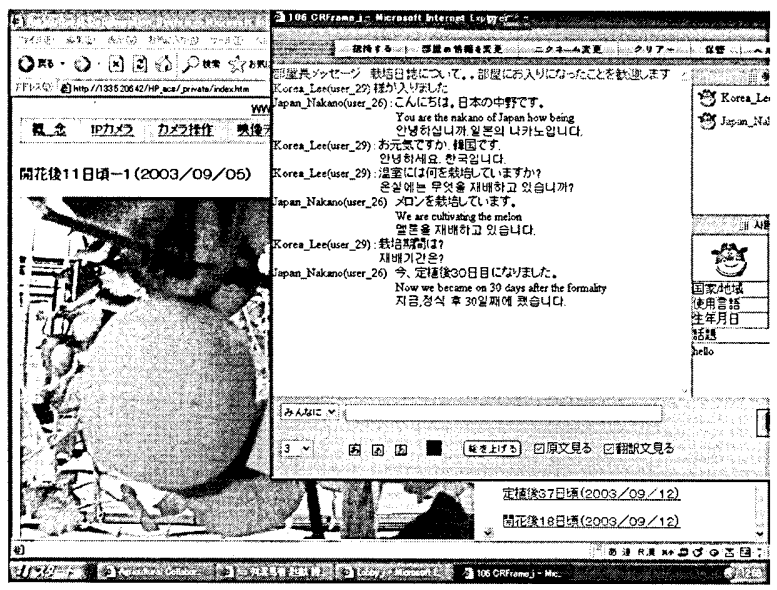

Fig. 8. Example of text chatting screen by using Web ASP translation service. 
ment in Korean language, and the Japanese farmer can use Japanese language. It is necessary to improve the translation accuracy of agricultural technical terms more, though the translation chat was able to practice by using the Web ASP translation service of Mobico \& Sysmeta.

\section{CONCLUSIONS}

The basic terminology translation dictionary was developed by using several open source programs and free software to translate the basic terminology on the screen of multilingual collaboration system. It was composed of about 4200 terms such as 2700 horticulture terms, 1300 agricultural machinery terms, and 150 file names in Japanese, Korean and English. By the registration and editing subsystem, other terms could be added easily to the dictionary through the Internet. It was obtained that the basic terminology translation dictionary was useful for the perfect translation of not only the terms on the collaboration screen but also the retrieval terms for multilingual search engine system. Farmers could practice the exchange of opinions and the joint works in their native languages on the multilingual collaboration system of agricultural production.

\section{REFERENCES}

Choi, H. M., S. M. Park, J. H. Kang, H. K. Kim and H. M. Choi 2002 Tele-medical imaging conference system based on the Web. Computer methods and programs biomedicine, 68: 223-231

Cunha, R. S., A. M. Saraiva, C. E. Cugnasca and A. R. Hirakawa 2001 An internet-based monitoring system for behaviour studies of stingless bees. EFITA2001, 1: 279-284

Herath, A., Y. Hyodo, Y. Kunieda, T. Ikeda and S. Herath 1996 Bunsetsu-Based Japanese-Sinhalese translation system. Information sciences, 90: 303-319

Laurenson, M., A. Otuka and S. Ninomiya 2002 Developing agricultural models using MetBroker mediation software. Journal agricultural meteorological, 58(1): 1-9

Lee, K. O. and K. Nakaji 2003 Development of the multilingual collaboration system for agricultural production by using IP camera. In "Proceedings of the international workshop on agricultural engineering and agro-products processing toward mechanization and modernization in agriculture and rural areas, Hochiminh, Vietnam", Agricultural publishing house 2004, pp114-124

Lin, Q., C. P. Low, J. M. Ng, J. Bu and X. Lin 2003 Multiuser collaborative work in virtual environment based CASE toll. Information and software technology, 45: 253-267

Lopes, A. A., C. E. Cugnasca and A. M. Saraiva 2001 Remote interface for an environment control system using the Internet. EFITA 2001, 2: 525-530

Mankai, C. and A. Mili 1995 Machine translation from to English and French. Information sciences, 3: 91-109

Nakaji, K. and K. O. Lee 2002 Construction of the multilingual collaboration system for farmers. ISMAB 2002, 2: 721-726

Nakamura, N. and S. Takigishi 2001 Multilingual list system for Japanese and Korean farmers. EFITA 2001, 1: 239-243

Park, S. Y. and G. R. Oh 1999 Machine translation in Korea. MT-Summit VII: 100-104

Tou, J. T. 2000 An intelligent full-text Chinese-English translation system. Information sciences, 125: $1-18$ 